\title{
Adorno e o jazz
}

\section{Elder Kôei Itikawa Tanaka*}

\section{Resumo}

Este artigo pretende, a partir de algumas das formulações de Theodor Adorno sobre o jazz, apresentar o diálogo estabelecido entre Adorno e seus críticos. Nosso objetivo é procurar compreender as afirmações do crítico cultural alemão sobre esse gênero musical, além de entender as especificidades do jazz como forma musical norte-americana do início do século XX.

\section{Palavras-chave}

Theodor Adorno. Jazz. Estudos Culturais. Música.

O surgimento e evolução do jazz são descritos pelos seus historiadores como momentos singulares dentro da história da música norte-americana. Os motivos para essa relevância histórica residem em dois fatores principais: primeiro, no grau de evolução técnica alcançado pelos músicos em um curto espaço de tempo; e segundo, a importância do jazz na esfera social, uma vez que suas origens estão diretamente ligadas à história dos negros norte-americanos no fim do século XIX e início do século $X X$ - período em que, mesmo em meio à segregação racial, os músicos negros foram capazes de criar e desenvolver um gênero musical inovador que rapidamente ganhou adeptos no mundo todo.

Tal reconhecimento da relevância histórica do jazz como forma de arte, no entanto, não é uma unanimidade. Um dos exemplos mais famosos dessa discussão no campo da teoria crítica musical se encontra no debate proposto por Theodor Adorno em seus ensaios sobre música. Apresentaremos a seguir algumas das opiniões de Adorno sobre o jazz e a música popular em geral, e o diálogo que estudiosos como J. Bradford Robinson e Peter Townsend estabeleceram com o crítico cultural alemão.

Em "O fetichismo na música e a regressão da audição" (ADORNO, 1999, p. 65108), Adorno faz uma crítica à situação da música ocidental como um todo. Segundo o crítico, houve uma inversão de valores da Grécia clássica para os tempos modernos. Se na Grécia Antiga a função disciplinadora da música era uma qualidade, hoje todos tendem a "obedecer cegamente à moda musical, aliás, como acontece igualmente em outros setores" Tal processo teve duas consequências: a fetichização da música e a regressão da audição. Na primeira, a música é transformada em mercadoria consumida, e aqueles que a consomem "fabricam" o sucesso, coisificam-no e o

\footnotetext{
${ }^{*}$ Doutorando em Letras na FFLCH-USP.
} 
aceitam como critério objetivo sem se reconhecer nele. Na segunda, a audição moderna permanece num estado infantil, conservador, pois rejeita toda e qualquer música que saia da ordem pré-estabelecida. Neste mesmo ensaio, Adorno cita Walter Benjamin acerca do cinema em comparação com a música:

A observação de Walter Benjamin sobre a percepção de um filme em estado de distração também vale para a música ligeira. O costumeiro jazz comercial só pode exercer a sua função quando é ouvido sem grande atenção, durante um bate-papo e, sobretudo, como acompanhamento de baile. [...] Contudo, se o filme como totalidade parece ser adequado para a apreensão desconcentrada, é certo que a audição desconcentrada torna impossível a apreensão de uma totalidade (ADORNO, 1999, p. 93).

Adorno afirma que o jazz é somente mais um braço da indústria cultural, um "fenômeno de massa" sujeito a todas as limitações como obra de arte dentro do capitalismo quanto o cinema ou a fotografia, e desvaloriza as improvisações características do gênero. Afetadas pela "estandardização, a exploração comercial e o enrijecimento do meio", as improvisações do jazz são consideradas por Adorno meros embustes:

\begin{abstract}
as chamadas improvisações nada mais são que paráfrases de fórmulas básicas, sob as quais o esquema, embora encoberto, aparece a todo instante. Até mesmo as improvisações são em certo grau normatizadas, e sempre voltam a se repetir. [...] Diante das enormes possibilidades de invenção e tratamento do material musical até mesmo, quando absolutamente necessário, na esfera do entretenimento -, o jazz apresenta-se em um estado de completa indigência. O que ele utiliza das técnicas musicais disponíveis é inteiramente arbitrário (ADORNO, 2001, p. 119).
\end{abstract}

Seguindo esse raciocínio, para Adorno o jazz é ruim porque desfruta dos vestígios do que foi imposto aos negros, ou seja, a falta de liberdade e a sua condição submissa ao mercado.

A vida no capitalismo tardio é um rito permanente de iniciação. Todos devem mostrar que se identificam sem a mínima resistência com os poderes aos quais estão submetidos. Isso se encontra na base da síncope do jazz que escarnece dos tropeços e, ao mesmo tempo, os eleva à condição de norma (ADORNO, 2002, p. $54)$.

Peter Townsend, em Adorno on Jazz: Vienna versus the vernacular (1988, p. 6988), responde ao ensaio "Moda intemporal - sobre o jazz" (ADORNO, 2001, p. 117130), de Adorno, ao afirmar que o raciocínio do crítico alemão "pode ser resumido como uma tentativa de identificar o jazz como um típico fenômeno de massa" (TOWNSEND, 1988, p. 69 - tradução nossa). Além disso, "o perigo do jazz, na visão de Adorno, é que ele possibilita aos seus adeptos imitar as atitudes da dissidência e da rebeldia enquanto completa sua escravização às ordens do mercado" (TOWNSEND, 1988 , p. 70 - tradução nossa). 
Townsend divide suas críticas em três partes: na primeira, afirma que o crítico alemão simplesmente não conhece o jazz. Argumenta que sua falta de conhecimento sobre o assunto é tamanha que é surpreendente o fato de ele se sentir preparado para discorrer sobre o jazz e justapor esse ensaio aos seus textos sobre Schoenberg e J. S. Bach, nos quais demonstra conhecimento técnico detalhado. A segunda crítica é em relação aos artifícios retóricos utilizados por Adorno para desqualificar opiniões contrárias à dele. A última crítica de Townsend é em relação à ausência de meio-termo entre arte elevada e aquela absorvida pela indústria cultural. "Existe ou a intransigência criativa (que tem como arquétipos as versões de Adorno de Schoenberg e Bach) ou a completa absorção [pelo mercado] [...]. Nenhuma outra relação entre arte e sociedade é prevista ou, como parece, permitida" (TOWNSEND, 1988, p. 69-70 - tradução nossa).

Sobre a falta de conhecimento de Adorno em relação ao jazz, Townsend cita a seguinte passagem de "Moda intemporal":

O jazz é uma música que combina a mais simples estrutura formal, melódica, harmônica, e métrica com um decurso musical constituído basicamente por síncopas de certo modo perturbadoras, sem que isso afete jamais a obstinada uniformidade do ritmo quaternário básico, que se mantém sempre idêntico (ADORNO, 2001, p. 117).

Townsend afirma que a uniformidade do ritmo do jazz não exclui a variedade (na verdade, os melhores músicos são julgados em parte pela sutileza e flexibilidade com que lidam com esse ritmo básico). A falha de Adorno na avaliação estética desse recurso é ainda mais evidente ao afirmar que o ritmo do jazz sustenta-se de maneira "idêntica" no ritmo quaternário. De acordo com Townsend, isso deixa claro que, para o ouvido de Adorno, o ritmo do jazz "consiste em uma sucessão inviolável e invariável de compassos de quatro tempos, tão estéreis e monótonos quanto os tiques de um relógio" (TOWNSEND, 1988, p. 72 - tradução nossa).

Uma das causas desse equívoco de Adorno com relação à natureza rítmica do jazz vem de sua interpretação simplista do termo "síncope". Townsend explica que, para Adorno, a síncope do jazz se dá unicamente na ênfase das batidas normalmente fracas do compasso, produzindo tensão entre essa acentuação e o padrão esperado. Adorno restringe-se ao modelo abstrato e não busca em nenhum momento uma experiência de como tal princípio se realiza. "Síncope", no sentido restrito de que Adorno se utiliza, é apenas um recurso entre uma infinidade de recuos, suspensões, cruzamentos e multiplicações de frases rítmicas. Esse amplo repertório de possibilidades faz parte de uma experiência consistente e bem documentada de milhões de ouvintes durante 70 anos de história do jazz. Para Townsend, Adorno mostra uma inaptidão para escrever de maneira séria sobre o assunto que seria escandalosa se fosse aplicada a uma das artes "elevadas" (TOWNSEND, 1988, p. 73).

Sobre os artifícios retóricos de Adorno, Townsend retira um exemplo, dentre outros, do que ele chama de "figuração não-acidental", ou seja, "uma maneira de estabelecer um paralelo, sugerir um vínculo, até mesmo uma ligação causal, sem a obrigação de fornecer qualquer tipo de comprovação" (TOWNSEND, 1988, p. 75 tradução nossa): 
Enquanto nas ditaduras europeias os líderes das duas tendências totalitárias bradavam contra o aspecto decadente do jazz, a juventude de outros países já se deixava eletrizar pelas danças sincopadas, cujas bandas se originaram, não por acaso, de bandas militares (ADORNO, 2001, p. 126).

Analisando a estrutura sintática da oração e as pressuposições de Adorno, Townsend estabelece o seguinte diagrama, que constitui uma relação entre música (à esquerda) e política (à direita):

música militar<smiles>[13CH3]</smiles>

bandas de jazz

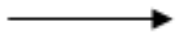

totalitaris mo

ditadura sobre as massas

O jazz está para uma forma de ditadura assim como as marchas estão para outra. [...] Nos é dito que as bandas de jazz, "não por acaso têm origem na música militar". Em outras palavras, há uma conexão genética entre ambas, cujo significado mais amplo é sugerido pela frase "não por acaso". O significado exato dessa descendência genética não é explicitado por Adorno, mas sua sugestão ambígua dá sinais de que há mais nela do que circunstâncias históricas. [...] Certamente não foi por acaso, mas por força das circunstâncias econômicas que as bandas militares foram uma das influências no desenvolvimento dos grupos de jazz. Mas o que Adorno dá a entender não é nada mais do que um mero vínculo histórico: a frase "não por acaso", nesse contexto, pode ser tomada como "por causa de uma profunda similaridade na sua natureza e função" (TOWNSEND, 1988, p. 76 - tradução nossa).

Um dado importante sobre a história do jazz, fundamental para a melhor compreensão do raciocínio de Townsend, é o fato de que o primeiro contato que os exescravos tiveram com instrumentos industrializados se deu por meio das sobras das bandas militares da Guerra Civil (PERETTI, 1994, p. 13). A marcha produzida por tais bandas é um gênero musical que reproduz, em termos marxistas, o trabalho alienado, estabelecendo uma distinção entre criação e execução no processo produtivo. Sendo assim, o músico não tem liberdade individual para exercer sua capacidade criativa perante a partitura escrita pelo compositor ou os comandos do regente. Uma das maiores contribuições do jazz à música ocidental foi justamente a ruptura desse modo de produção na música, posto que os improvisos simultâneos dos músicos de jazz nada mais são do que criação simultânea à execução.

Em outro trecho de "Moda intemporal", Adorno afirma que

é possível que os Negro Spirituals, forma precursora do Blues, tenham unido, enquanto música de escravos, o lamento sobre a falta de liberdade à sua confirmação submissa. Aliás, é muito difícil isolar os elementos autenticamente negros no jazz. É certo que o lumpemproletariado branco tomou parte na préhistória do jazz antes de este ter sido iluminado pelos holofotes de uma sociedade que parecia estar à sua espera, já familiarizada pelo Cake-walk e pelo sapateado, com os seus impulsos (ADORNO, 2001, p. 119), 
Na sua terceira e última crítica, Townsend faz comentários sobre o trecho acima. Segundo ele, as

\begin{abstract}
"Canções de escravos" em geral, ao que parece, confirmam a escravidão e, por isso, são desprovidas de valor. Também não poderíamos esperar a contribuição correta do "lumpemproletariado branco", que não só divide a opressão desvalorizante do negro, mas também atrapalha o processo de isolamento dos "elementos autenticamente negros".

Essa passagem revela dois importantes aspectos do campo no qual a teoria de Adorno está situada. Primeiro, se estamos buscando contribuições válidas a uma cultura corrompida, não deveríamos procurá-las em nenhuma das classes baixas. Segundo, podemos observar no uso da palavra "autêntica" uma orientação subjacente à pureza dos elementos que também é manifestada em outros de seus ensaios. [...] [De acordo com Adorno], produtos culturais de valor não se originarão nas classes oprimidas da sociedade, cuja escravidão projeta-se sobre suas criações, as quais, deste modo, voluntariamente colocam-se à mercê da exploração pela sociedade do consumo. A cultura também é um tanto retilínea: é importante distinguir, por exemplo, música de salão da música séria, dado que o desenvolvimento significativo ocorre somente na última. (TOWNSEND, 1988, p. 8182 - tradução nossa)
\end{abstract}

De acordo com J. Bradford Robinson (1994, p. 1-25), os ensaios de Adorno sobre jazz, embora escritos entre 1933 e 1953, após a queda da República de Weimar, estão intimamente conectados com a música produzida na Alemanha dos anos 1920, e devem ser tratados levando-se esse fato em consideração. Mesmo seus últimos ensaios sobre o gênero, em vez de reconsiderarem sua opinião sobre o assunto, têm o objetivo de atualizar suas ideias sobre a música comercial da década de 1920, ou corrigir algumas de suas deficiências. "Moda intemporal - sobre o jazz", de 1953, por exemplo, é escrito no momento em que Adorno já havia retornado dos Estados Unidos, e resume vinte anos de reflexões sobre o gênero, corrigindo alguns equívocos conceituais cometidos anteriormente. No entanto, as conclusões gerais a que chegou sobre o jazz nas duas primeiras décadas do século XX são aplicadas anacronicamente e ele é reestabelecido como "a música do fascismo". Embora essa visão seja perfeitamente aplicável à música comercial alemã dos anos 1920, no caso do jazz norte-americano ela foi contestada por vários críticos da época (ROBINSON, 1994, p. 3). Adorno respondeu a um deles, Joachim-Ernst Berendt, em um ensaio intitulado "Réplica a uma crítica a 'Moda intemporal'" (ADORNO, 2001, p. 281-285):

Não acuso o jazz por sua selvageria ou anarquia, mas por sua docilidade e seu caráter convencional. As dissonâncias e efeitos como as dirty notes não possuem em nenhum lugar uma função harmônica constitutiva, são sempre meros ingredientes estimulantes adicionados à harmonia tradicional. Por isso os "sons falsos" que não existem em Schoenberg (ADORNO, 2001, p. 283).

Em "Introdução à sociologia da música" (1962), Adorno revê o uso do termo "jazz" e o substitui por leichte Musik (música popular), mas suas conclusões são praticamente as mesmas: o jazz não pode ter status de arte por ser cooptado constantemente pela indústria cultural. Nesse último texto, Adorno denuncia sua insistência na primazia da composição escrita em detrimento à performance improvisada. De acordo com Adorno, as conquistas dos músicos de jazz dentro das restrições impostas pelo gênero não são mais importantes do que a existência de tais restrições (ROBINSON, 1994, p. 3). 
Robinson enumera alguns motivos que justificam a opinião de Adorno em relação ao jazz. O primeiro deles diz respeito à recepção do gênero na Alemanha nas primeiras décadas do século XX. Enquanto Londres e Paris recebiam músicos como Sidney Bechet e discos da Original Dixieland Jazz Band eram vendidos livremente na Europa Ocidental, a Alemanha ainda se encontrava isolada cultural e economicamente pelo bloqueio imposto pelos países Aliados. Não havia importação de gramofones e nenhum artista norte-americano visitava o país. Como a demanda da classe médiaalta urbana por música para dançar crescia cada vez mais, esse isolamento fez com que os artistas alemães produzissem uma música (denominada genericamente como "jazz") a partir de suas próprias tradições de música comercial, às quais foram aplicadas as vagas noções do jazz norte-americano que eles possuíam até aquele momento. Dessa maneira, o jazz alemão surgiu da união de "síncopes corrompidas do ragtime" e um estilo de performance desinibida a três gêneros de música comercial herdadas do período da Alemanha Imperial: a banda militar, a orquestra de salão e a Radaukapelle - música vienense de salão tocada de maneira deliberadamente distorcida por músicos-palhaços. Desses três gêneros, no entanto, foi o segundo que obteve maior destaque nas origens do jazz alemão. A orquestra de salão, liderada por um violinista solo (Stehgeiger), é originária dos cafés vienenses e já carregava tradicionalmente a improvisação, que poderia ser adaptada ao jazz. Bastava uma pequena alteração no som que essas orquestras produziam para que fossem viabilizadas comercialmente e rebatizadas como "bandas de jazz". Aos olhos do público alemão do início do século $\mathrm{XX}$, um violinista de origem húngara ou eslava era considerado um músico típico de jazz (ROBINSON, 1994, p. 4-5). Do ponto de vista adorniano, assim como para outros críticos de sua época, dos quais muitos não tinham sequer pisado em solo americano, o jazz era considerado um fenômeno da Europa Central, e podia ser perfeitamente entendido sob categorias centro-europeias (ROBINSON, 1994, p. 14).

A partir desse momento, diversos subgêneros do jazz alemão surgiram, mas todos eles tinham uma relação muito tênue com a música popular norte-americana e nenhuma relação com a música produzida por Louis Armstrong ou Sidney Bechet. Quando finalmente houve um desenvolvimento do aparato técnico no mercado fonográfico e a exportação de discos frágeis de goma-laca foi substituída pela de matrizes metálicas, os álbuns de jazz gravados pelas race records foram praticamente ignorados pelo mercado alemão. A maioria das importações era composta por discos gravados por artistas brancos, principalmente Paul Whiteman, cujo conceito de "jazz sinfônico" influenciou o jazz alemão produzido a partir de sua turnê pela Europa em 1926 (ROBINSON, 1994, p. 5-7).

De acordo com Robinson, Adorno teve contato com todos esses subgêneros musicais na Alemanha. Embora todos fossem reconhecidos popularmente sob a mesma alcunha de "jazz", o crítico cultural alemão foi capaz de identificar as diferenças entre cada um deles, usando uma terminologia própria e adotando-a sem alterações até seus últimos ensaios sobre o gênero, apesar de vários outros estilos de jazz terem surgido nesse período nos Estados Unidos (swing, bebop, cool jazz). A música produzida pelos negros norte-americanos, por exemplo, com o qual Adorno teve contato em meados da década de 1930, foi denominado Jazz-Excentric - as 
características próprias desse jazz (timbre vocalizado, influências do blues, efeitos instrumentais expressivos) eram excentricidades pessoais, que mantinham a substância intacta. Dessa maneira, o jazz de solistas como Louis Armstrong era considerado por Adorno como um fenômeno marginal dentro da música comercial como um todo. Para ele, o termo "jazz" representava as mais variadas formas de música popular: da música dançante sincopada dos anos 1920 ao som das big bands dos anos 1930 e 1940 (ROBINSON, 1994, p. 7-9). Segundo Robinson, Adorno aplicou ao jazz produzido ao longo de cinco décadas o mesmo vocabulário técnico que ele utilizou para avaliar a música comercial alemã dos anos 1920. Suas conclusões se mantiveram as mesmas tanto quanto a sua terminologia analítica (ROBINSON, 1994, p. 13). Nunca ocorreu a ele, por exemplo, que a estrutura rígida sobre a qual o jazz é desenvolvido pudesse ser, na verdade, um pré-requisito à improvisação, que precisa manter alguns parâmetros intactos para que outros sejam explorados (ROBINSON, 1994, p. 10). Os limites do jazz, de acordo com Adorno, são resultado de sua função como música para dançar, ou seja, como mercadoria. Devido à sua natureza específica, de acordo com Robinson, é necessária, na avaliação do jazz, outro tipo de abordagem crítica, distinta daquela em relação à "música de arte" (ROBINSON, 1994, p. 13).

Para Adorno, o jazz é conservador porque o improviso não é um espaço aberto. A tendência do senso comum é entender o improviso como uma espécie de liberdade ensaística, como a que fora definida pelo próprio Adorno em seu "O ensaio como forma" (2003, p. 15-46), ou seja, uma forma aberta. Para ele, o improviso do jazz é uma fuga controlada. Mesmo quando esse controle é rompido, a música acaba voltando à estrutura da qual havia escapado momentaneamente. Desse modo, do ponto de vista adorniano, o jazz sempre acaba retornando ao conformismo. Tal fato, no entanto, não é suficiente para que ele diga que o jazz é uma música regressiva sua opinião está provavelmente ligada à falta de um entendimento das origens do jazz nos EUA, de acordo com o que Robinson aponta em seu ensaio.

Assim como seus contemporâneos alemães, Adorno nega que o gênero tenha nascido entre os negros norte-americanos. Para ele, o jazz é uma música de brancos que suplantou algumas tradições negras norte-americanas, como os spirituals e o ragtime - Adorno não faz menção à música gospel ou ao blues rural. O crítico alemão chega a afirmar que "a cor da pele dos negros, assim como o prateado dos saxofones, é um efeito cromático" (ADORNO apud ROBINSON, 1994, p. 13 - tradução nossa) útil como função propagandística. Mesmo em seus últimos textos, Adorno ateve-se à ideia de que os negros não adicionaram nada ao jazz além da cor de sua pele: "Não tenho nenhum preconceito contra os negros, exceto que nada, a não ser a cor, os distingue dos brancos" (ADORNO, 2001, p. 285). Tal opinião pode ser entendida se relacionada à música comercial produzida na República de Weimar, conforme descrevemos anteriormente. Naquele contexto, o "jazz" passou por um desenvolvimento totalmente distinto ao seu correspondente norte-americano, pois na Alemanha ele era executado, ouvido, comercializado, consumido, dançado e produzido em larga escala por brancos. Não é de se espantar, portanto, que Adorno conclua que qualquer característica da música dos negros norte-americanos tenha sido erradicada no decurso da evolução social do gênero (ROBINSON, 1994, p. 14). 
Robinson também ressalta o conceito de canção popular para Adorno. Segundo o crítico alemão, não era um gênero separado da música comercial, mas uma parte central do jazz em si. Nas primeiras décadas do século XX na Alemanha, as partituras de canções populares eram amplamente publicadas e vendidas em formato impresso, ao contrário dos discos, cujo acesso era bem mais restrito. As partituras impressas constituíam, dessa maneira, o núcleo da música comercial na República de Weimar, e podiam ser estudadas e analisadas com uma facilidade muito maior do que as gravações ou as performances propriamente ditas. Foi a partir dessas partituras que Adorno, um defensor da primazia da escrita musical, pôde identificar estilos e subcategorias do jazz. Também foi por meio da comparação dessas partituras com a performance de algumas bandas que ele chegou à conclusão de que havia mais músicos qualificados entre os arranjadores do que entre os compositores de jazz. Porém, como a inventividade dos arranjos do jazz é limitada pelas melodias de 32 compassos e pelos padrões harmônicos do substrato composicional, a inventividade também está fadada à banalidade (ROBINSON, 1994, p. 16).

Também podemos destacar o trecho de Über Jazz (ADORNO, 1982, p. 70-100) que Robinson nos traz. Nele, Adorno disserta sobre a decadência do jazz conforme alcança os níveis mais baixos da sociedade:

Quanto mais o jazz desce os degraus da sociedade, mais traços reacionários ele adota, mais completa é a sua subserviência à banalidade, menor é a paciência em relação à liberdade e às manifestações da imaginação, até que, finalmente, como acompanhamento musical da moda coletiva, ele pouco faça além de glorificar a supressão em si mesma. Quanto mais democrático é o jazz, pior ele se torna (ADORNO apud ROBINSON, 1994, p. 19).

Nesse excerto do texto de Adorno de 1937, Robinson nos chama a atenção para a descrição às avessas do processo de disseminação social do jazz nos EUA, mas que faz todo sentido no contexto alemão do início do século XX. Enquanto o jazz norteamericano surgiu em meio a uma minoria negra oprimida e alcançou a classe média branca por um processo de assimilação, o jazz alemão trilhou um caminho diametralmente oposto, pois foi introduzido pela minoria branca das classes sociais mais altas e então "imposto, em um processo dialético de imitação e marketing agressivo, nas camadas mais baixas da sociedade". Como os salões de dança alemães mais modestos não tinham recursos para contratar grandes bandas virtuosas de jazz, eles se contentavam com as transmissões radiofônicas, que traziam uma versão diluída do som das bandas ao vivo. A tendência das emissoras de rádio era contar com as próprias bandas em vez de procurar grupos musicais especializados (ROBINSON, 1994, p. 20).

De acordo com Adorno, o processo de decadência na música comercial alemã se deu por completo com a ascensão de Hitler em 1933, quando o jazz foi proibido, por meio de um decreto do governo alemão, de ser executado. Todos os músicos foram obrigados a tocar, daquele momento em diante, somente marchas militares. Do ponto de vista adorniano, 
as técnicas do jazz como o improviso, síncope, timbre vocalizado e as quebras instrumentais são somente ornamentos que mantém a essência da música inalterada: o pulso único, a métrica $4 / 4$, o período de oito compassos, a instrumentação restrita de sopros e percussão. Com esses ornamentos agora descartados, somente a substância subjacente do jazz permanece, uma substância idêntica à marcha militar (ADORNO apud ROBINSON, 1994, p. 20-21 - tradução nossa).

Não é surpresa alguma para Adorno que o jazz produzido na Alemanha tenha se curvado com tamanha rapidez aos usos do fascismo. De acordo com Robinson, "o jazz, em sua transformação final, provou ser a música do reacionarismo político. A história do jazz alemão, sociologicamente decifrada, equipara-se à queda da própria República de Weimar" (ROBINSON, 1994, p. 21). Ao levar esse paralelismo em consideração, Robinson reconhece Adorno não só como um teórico sociocultural, mas também como um observador astuto da música popular de sua época, capaz de analisar esteticamente a música popular de Weimar e entender, "mais do que qualquer um à sua época, as origens peculiares, a estrutura musical, os pré-requisitos institucionais e a predestinada queda dessa singular forma musical alemã" (ROBINSON, 1994, p. 22 tradução nossa).

Dois pontos nas observações de Robinson sobre Adorno e sua relação com o jazz nos chamam a atenção. Em primeiro lugar, a precipitação do crítico alemão ao querer universalizar suas conclusões sobre o jazz a partir de um contexto musical muito específico. Em segundo lugar, a insistência de Adorno em aplicar pressupostos da escrita musical europeia para avaliar um gênero cujas origens se encontram em uma tradição oral aparada por uma matriz africana e que é baseado na performance. Para Adorno,

as grandes obras de musicais que ainda hoje têm algo a dizer - a música "viva" formaram-se a partir do momento em que o recuo da improvisação deu lugar à obra de arte fixada e com texto unívoco. Sem uma notação precisa e unívoca nada teria sido possível, não apenas o conceito que se limita ao desamparado "romantismo", mas também a música que vai de Haydn e Mozart a Schoenberg e Webern, incluindo a parte propriamente polifônica da obra de Bach (ADORNO, 2001, p. 282).

A defesa da primazia da escrita musical é reflexo de sua proposta de crítica negativa e seu conceito de autonomia da obra de arte. Para Adorno, ao negar o horror, a barbárie e a sociedade de massas, a música consegue estabelecer um poder de crítica, caracterizando um investimento na linguagem como reação à barbárie.

As grandes obras de arte $e$ as construções filosóficas permaneceram incompreendidas não por sua distância grande demais do âmago da experiência humana, mas pela razão contrária, e a própria incompreensão poderia ser facilmente reduzida a uma compreensão demasiado grande: a vergonha de participar da injustiça universal, que se tornaria insuportável a partir do momento em que as pessoas se permitissem compreender (ADORNO, 1993, p. 129).

No âmago da crítica adorniana existe a defesa de que essas obras de arte, que aparentemente se afastam da sociedade, guardam aquilo que é mais humano: a 
lucidez em relação à barbárie. Essa incompreensão vem da tentativa de se proteger desse horror de participar da barbárie. Wisley Francisco Aguiar nos ajuda a compreender esse conceito ao afirmar que

\begin{abstract}
[Adorno] contrapõe os produtos da indústria cultural com o sentido de obra de arte autêntica e autônoma. A arte autônoma possui um valor de verdade, pois se mostrava muito distante da precária condição material humana e, ao mesmo tempo, se manifestava como protesto à ordem vigente. Quando a arte protesta negando o âmbito das relações socioeconômicas, ela atrai para si uma "promessa de felicidade", que significa afirmar no contexto da obra uma possibilidade para o futuro. Mas a arte autônoma não era tão acessível às massas, justamente pelo esforço cognitivo que exigia de quem a apreciasse. Contudo, isso não significa um pretexto para torná-la fácil. É em sua difícil compreensão que a arte resiste à falsa universalidade da integração, e seu valor de verdade se mostra preservado, além de sua seriedade designar um aspecto de denúncia contra a falsa organização social. As massas estavam mais ligadas a uma arte de entretenimento, que servia de "descanso". Assim, arte séria e arte ligeira se mostravam irreconciliáveis, mas a indústria cultural fez uma forçosa união entre essas duas esferas, cujo resultado se vê na banalização da obra autêntica (AGUIAR, 2008).
\end{abstract}

Em um ponto diametralmente oposto ao de Adorno, David Stowe relata um movimento liderado por jornalistas e críticos culturais de esquerda contemporâneos ao swing $^{1}$, que viam no jazz um conteúdo político diretamente relacionado à ideologia da Frente Popular. "Para esses simpatizantes, o jazz era, acima de tudo, uma música democrática, um produto 'do povo', acessível a todas as classes e tipos de cultura, marcada tanto pelo espírito de cooperação coletiva como pela espontaneidade individual" (STOWE, 1996, p. 53 - tradução nossa).

Em oposição a Adorno, esses críticos exaltavam a relação dos negros com a música, ao ponto de afirmar que o jazz é "a música do proletariado americano. Se os negros se sobressaem no seu desenvolvimento, é porque mais negros são proletários" (STOWE, 1996, p. 66). Contudo, Michael Denning nos explica que o swing

não era uma cultura "proletária" da mesma forma que o teatro radical; pelo contrário, o swing, assim como Tin Pan Alley, o cinema de Hollywood e as transmissões de rádio, era uma cultura comercial de massa que forjou um estilo "americano" a partir dos estilos urbanos das classes trabalhadoras negras e étnicas (DENNING, 1996, p. 330 - tradução nossa)

O fato é que poucos músicos se tornaram ativistas de esquerda e pensavam em si mesmos como artistas politizados, dado que seus interesses voltavam-se aos seus ofícios e suas preocupações políticas se limitavam a problemas como as injustiças com

1 Estilo de jazz surgido em meados da década de 1930 e cuja denominação praticamente substituiu o termo jazz na época, que passou a ser usado quase exclusivamente para descrever a música produzida em Nova Orleans na década anterior. O swing é caracterizado por uma nova virtuosidade por parte dos músicos - que avançaram no que diz respeito às bases harmônicas e melódicas do jazz; uma evolução no uso da guitarra com o surgimento do amplificador e a inclusão do saxofone como instrumento da seção melódica; surgimento das big bands, compostas por 12 a 18 músicos; e o desenvolvimento das composições de jazz para essas bandas. "Se o jazz da década de 1920, criado numa época de afluência, iluminava um individualismo desafiador, a Era do Swing respondeu aos anos de adversidade e de guerra com um espírito coletivo que expressava um despreocupado otimismo" (GIDDINS, G., DEVEAUX, S., 2009, p. 171-172 - tradução nossa). 
os músicos, discriminação racial e explorações trabalhistas. No entanto, segundo Michael Denning, eles reconheciam a crise social decorrente da Depressão e do fascismo, e simpatizavam com os ideais da Frente Popular, pois participaram de concertos beneficentes do movimento (DENNING, 1996, p. 333).

De acordo com Stowe, todavia, esse alinhamento do jazz com a esquerda da época é suspeito justamente por causa da inserção do jazz no mundo do consumo. Mesmo não sendo radical como Adorno, Stowe nos alerta que

\begin{abstract}
as contradições de classe embutidas na produção e no consumo do swing tornaram difícil para a música manter a força simbólica que os seus entusiastas de esquerda gostariam que ela tivesse. [...] [Ao mesmo tempo que] para alguns críticos o swing aderia de maneira incompleta à política marxista, para outros ele se tornou símbolo de uma ideologia mais ampla dos anos 1930 - uma versão do excepcionalismo norte-americano, o qual defendia que os Estados Unidos eram o país das oportunidades econômicas e sociais, do pluralismo étnico, da liberdade de expressão, da ilimitada energia criativa. E enquanto esses ideais eram contemplados de maneira imperfeita na sociedade como um todo, eles atingiam sua maior expressão, de acordo com aqueles que os propunham, no reino musical do swing (STOWE, 1996, p. 72 - tradução nossa).
\end{abstract}

Não há como negar que na sociedade capitalista os bens de cultura sofram mudanças constitutivas. Na música isso se dá com o processo de padronização, a repetição de fórmulas, a absorção da "pornografia musical que é fabricada para satisfazer às supostas ou reais necessidades das massas" (ADORNO, 1999, p. 85). O jazz, como música popular, não escapa desse processo. Benny Goodman e Glenn Miller, por exemplo, produziam um jazz com um verniz de mercadoria muito evidente. Nossa crítica com relação à posição de Adorno é justamente o fato de sua visão estar restrita ao conceito de indústria cultural, que equipara os níveis de expressão estética popular num único patamar. Para Adorno, em nenhum desses níveis é possível enxergar um mapeamento progressivo. Tudo é degradação. Essa abordagem impede-o de perceber no jazz do início do século XX um horizonte de possibilidades. Nesse momento da História, o músico negro já havia saído do sul escravista e, por meio da posse dos meios de produção e do domínio das forças produtivas, conquistou seu espaço nas cidades do norte do país. É notável a evolução em relação à situação anterior dos negros norte-americanos. $O$ fato desse horizonte de possibilidades ter sido solapado logo em seguida pelo próprio funcionamento da indústria cultural não tira o mérito do jazz, o qual, naquele momento específico, configurava uma forma de expressão cultural concreta capaz de descrever uma superação social realizada de fato.

\title{
Referências
}

ADORNO, Theodor. A indústria cultural - o Iluminismo como mistificação das

massas. In: Indústria cultural e sociedade. São Paulo: Paz e Terra, 2002.

Minima Moralia: Reflexões a partir da vida danificada. Tradução de Luiz Eduardo Bicca. 2a ed. São Paulo: Editora Ática, 1993. 
Moda intemporal - sobre o jazz. In: Prismas - crítica cultural e sociedade. São Paulo: Ed. Ática, 2001.

O ensaio como forma. In: Notas de Literatura I. São Paulo: Editora 34, 2003, p. 15-46.

O fetichismo na música e a regressão da audição. In: Theodor $W$. Adorno

- Textos Escolhidos. São Paulo: Editora Nova Cultural Ltda., 1999.

Réplica a uma crítica a "Moda intemporal". In: Prismas - crítica cultural e sociedade. São Paulo: Ed. Ática, 2001.

Über Jazz [pseud. Hektor Rottweiler] In: Zeitschrift für Sozialforschung, 1937, no 5. Reimpresso em Gesammelte Scrhiften, XII (1982), p. 70-100.

AGUIAR, Wisley Francisco. Adorno e a dimensão social da arte. In: Revista Urutágua - revista acadêmica multidisciplinar. No 15 - abr./mai./jun./jul. Paraná: Universidade Estadual de Maringá (UEM), 2008 http://www.urutagua.uem.br/015/15aguiar.htm - acessado em 10/10/2009.

DENNING, Michael. Cabaret Blues. In: The Cultural Front: The Laboring of American Culture in the Twentieth Century. New York: Verso, 1996.

GIDDINS, Gary., DeVEAUX, Scott. Jazz. New York: W. W. Norton \& Company, 2009. PERETTI, Burton. The Creation of Jazz - Music, Race, and Culture in Urban America. Urbana and Chicago: University of Illinois Press, 1994.

ROBINSON, J. Bradford. The jazz essays of Theodor Adorno: some thoughts on jazz reception in Weimar Germany. In: Popular Music. Cambridge: Cambridge University Press, Vol. 13, no 1, Jan. 1994.

STOWE, David. Between Conjure and Kapital. In: Swing Changes: Big-Band Jazz in New Deal America. Boston: Harvard University Press, 1996.

TOWNSEND, Peter. Adorno on Jazz: Vienna versus the Vernacular. In: Prose Studies. Vol. II, n. 1, May 1988.

\section{Title}

Adorno and jazz

\section{Abstract}

This article aims at presenting the dialogue between Theodor Adorno and his critics concerning the former's opinions on jazz. Our objectve is to comprehend the german critic's assertions on this musical genre and understand the specificities of jazz as a north-american musical form in the beginning of the twentieth century.

\section{Keywords:}

Theodor Adorno. Jazz. Cultural Studies. Music.

Recebido em 21/03/2012. Aprovado em 28/06/2012. 